\title{
USEFULNESS OF ANTIBIOTICS IN ACUTE EXACERBATIONS OF COPD
}

\author{
Sandhya Sivasankaran Nair', Reshmi Sasidharan Nair'2, Fathahudeen Abdul Rasheed ${ }^{3}$ \\ ${ }^{1}$ Senior Resident, Department of Pulmonary Medicine, MES Medical College, Perinthalmanna. \\ ${ }^{2}$ Assistant Professor, Department of Pulmonary Medicine, GMC, Trivandrum. \\ 3 Professor and HOD, Department of Pulmonary Medicine, TDMC, Alappuzha.
}

\section{ABSTRACT}

\section{BACKGROUND}

COPD is characterised by frequent exacerbations, mostly infective. These are usually treated with antibiotics, even when the aetiology is non-infective. The efficacy of antibiotics in this setting is controversial. Hence, the study was planned to look for any added advantage for antibiotics in COPD exacerbations.

Aim- To study the usefulness of antibiotics in acute exacerbations of COPD in a) reducing relapse of exacerbation and b) reducing duration of hospital stay.

\section{MATERIALS AND METHODS}

110 COPD patients admitted with an exacerbation, after excluding infection, were randomised into two groups. The treatment group received oral Amoxicillin for five days while the control group did not. They were followed up for two weeks to look for relapses. Duration of hospital stay was also noted.

Settings and Design- Randomised controlled trial done in Pulmonary Medicine Department, GMC, Trivandrum.

Statistical Analysis- SPSS version 11.0 was used. Chi square and student $t$ test were used for analysing variables.

\section{RESULTS}

The baseline characteristics of the two groups were comparable. The mean duration of hospital stay was $6.6 \pm 2.48$ in treatment group and $6.96 \pm 2.24$ in control group $(\mathrm{p}=0.421)$. The number of relapses in two weeks was almost similar in both the groups with no statistically significant difference.

\section{CONCLUSION}

Empirical antibiotics were not found to be useful in COPD exacerbations without clinical or radiological evidence of infection.

\section{KEYWORDS}

COPD, Exacerbation, Antibiotics, Infection.

HOW TO CITE THIS ARTICLE: Nair SS, Nair RS, Rasheed FA. Usefulness of antibiotics in acute exacerbations of COPD. J. Evolution Med. Dent. Sci. 2017;6(33):2672-2675, DOI: 10.14260/Jemds/2017/576

\section{BACKGROUND}

COPD is a common disease encountered by pulmonologists and is characterised by frequent exacerbations, mostly due to infective aetiology. According to Anthonisen, the exacerbations can be type 1,2 or 3 depending on the symptoms of increased dyspnoea, sputum volume or sputum purulence.(1) GOLD guidelines recommend use of antibiotics apart from the usual management, for exacerbations where sputum purulence is present or any combination of other symptoms where one of those is sputum purulence.(2) Antibiotic overuse is still prevalent in treating all exacerbations, though their usefulness is controversial. This study tried to find out whether use of antibiotics in acute exacerbation of COPD helps reduce the number of relapses and duration of hospital stay.

\section{MATERIALS AND METHODS}

This was a randomised control study done in the Pulmonary

Financial or Other, Competing Interest: None.

Submission 02-04-2017, Peer Review 15-04-2017,

Acceptance 18-04-2017, Published 24-04-2017.

Corresponding Author:

Dr. Reshmi Sasidharan Nair,

Assistant Professor, Pulmonary Medicine,

GMC, Trivandrum.

E-mail: reshmisathish@rediffmail.com

DOI: $10.14260 /$ jemds $/ 2017 / 576$
Medicine Department of GMC, Trivandrum. Sample size was calculated using the following formula after doing a pilot study of 20 cases.

Sample size $(\mathrm{n})=2 \mathrm{SD}^{2}\left(\mathrm{Z}_{\alpha / 2}+\mathrm{Z}_{\beta}\right)^{2} / \mathrm{d}^{2}$

$\mathrm{N}=55$ in each arm

110 COPD patients admitted in the department during the period of February to December 2009, with features of acute exacerbation as per Anthonisen criteria were included in the study. Those with definite clinical evidence of infection, new CXR infiltrates and those on mechanical ventilation were excluded. The patients were block randomised into treatment and control groups, 55 in each arm. All patients were given the standard treatment for COPD exacerbations according to GOLD guidelines. The treatment group, in addition, received oral antibiotic Amoxicillin $500 \mathrm{mg}$ thrice daily for five days. Patients were discharged once they satisfied the GOLD discharge criteria. The outcome variables studied were the number of days of hospital stay and the number of relapses in two weeks (Defined as return to the same or any other hospital with persistent or worsening symptoms within two weeks of discharge). The patients were followed up in two weeks to assess the number of relapses. Reduction in duration of hospital stay and reduction in number of relapses were taken as favourable outcomes.

Statistical analysis was done using SPSS version 11.0. Chi square and student $t$ test were used for analysis of variables. 
Ethical clearance was obtained from the Institutional Ethics Committee. Confidentiality of the study subjects were maintained at all stages of the study.

\section{RESULTS}

There were 55 patients each in treatment and control groups. The baseline characteristics of the two groups are summarised in Table 1.

\begin{tabular}{|c|c|c|c|c|}
\hline Variable & & $\begin{array}{c}\text { Treatment } \\
\text { Group } \\
(n=55)\end{array}$ & $\begin{array}{c}\text { Control } \\
\text { Group } \\
(n=55)\end{array}$ & $\begin{array}{c}P \\
\text { value }\end{array}$ \\
\hline Average Age & & $59.1 \pm 10.2$ & $60.5 \pm 11.5$ & 0.305 \\
\hline $\mathrm{M}: \mathrm{F}$ & & $51: 4$ & $51: 4$ & 1.000 \\
\hline $\begin{array}{l}\text { Disease } \\
\text { Severity }\end{array}$ & Grade 1 & 6 & 5 & \multirow{4}{*}{0.733} \\
\hline & Grade 2 & 28 & 30 & \\
\hline & Grade 3 & 15 & 17 & \\
\hline & Grade 4 & 6 & 3 & \\
\hline \multirow[t]{4}{*}{$\begin{array}{c}\text { Smoking } \\
\text { Index }\end{array}$} & Nil & 8 & 5 & \\
\hline & $<400$ & 17 & 17 & \\
\hline & $>400$ & 30 & 33 & \\
\hline & Average & $\begin{array}{c}543.2 \pm \\
449.7\end{array}$ & $\begin{array}{c}499.6 \pm \\
390.6\end{array}$ & 0.576 \\
\hline $\begin{array}{l}\text { Kitchen } \\
\text { Smoke }\end{array}$ & No & 49 & 48 & \multirow[t]{2}{*}{0.768} \\
\hline & Yes & 6 & 7 & \\
\hline $\begin{array}{c}\text { Cor } \\
\text { Pulmonale }\end{array}$ & Yes & 9 & 10 & 0.801 \\
\hline
\end{tabular}

Sputum culture reports of the patients are summarised in Figure 1. Majority of patients in both groups didn't have an organism isolated from their sputum sample. The study showed no significant relationship between sputum culture results and duration of hospital stay or number of relapses in both groups. The mean duration of hospital stay and the mean number of relapses among the treatment and control groups are shown in Figure 2 and Table 4 respectively. There was no significant relationship between the stage of COPD and the number of relapses in two weeks (Table 2). But the disease stage was found significant in the duration of hospital stay (Table 3).

\begin{tabular}{|c|c|c|c|c|c|c|}
\hline \multirow{3}{*}{ Group } & \multirow{3}{*}{$\begin{array}{c}\text { Disease } \\
\text { Stage }\end{array}$} & \multicolumn{4}{|c|}{ Relapse in Two Weeks } & \multirow{3}{*}{$\mathbf{p}$} \\
\hline & & \multicolumn{2}{|c|}{ No } & \multicolumn{2}{|c|}{ Yes } & \\
\hline & & Count & $\%$ & Count & $\%$ & \\
\hline \multirow{4}{*}{ Treatment } & Grade 1 & 3 & 12.0 & 3 & 10.0 & \multirow{4}{*}{0.845} \\
\hline & Grade 2 & 14 & 56.0 & 14 & 46.7 & \\
\hline & Grade 3 & 6 & 24.0 & 9 & 30.0 & \\
\hline & Grade 4 & 2 & 8.0 & 4 & 13.3 & \\
\hline \multirow{4}{*}{ Control } & Grade 1 & 1 & 3.8 & 4 & 13.8 & \multirow{4}{*}{0.159} \\
\hline & Grade 2 & 15 & 57.7 & 15 & 51.7 & \\
\hline & Grade 3 & 10 & 38.5 & 7 & 24.1 & \\
\hline & Grade 4 & 0 & 0.0 & 3 & 10.3 & \\
\hline & $\begin{array}{r}\text { Tabl } \\
\text { Numbe }\end{array}$ & & & & & \\
\hline
\end{tabular}

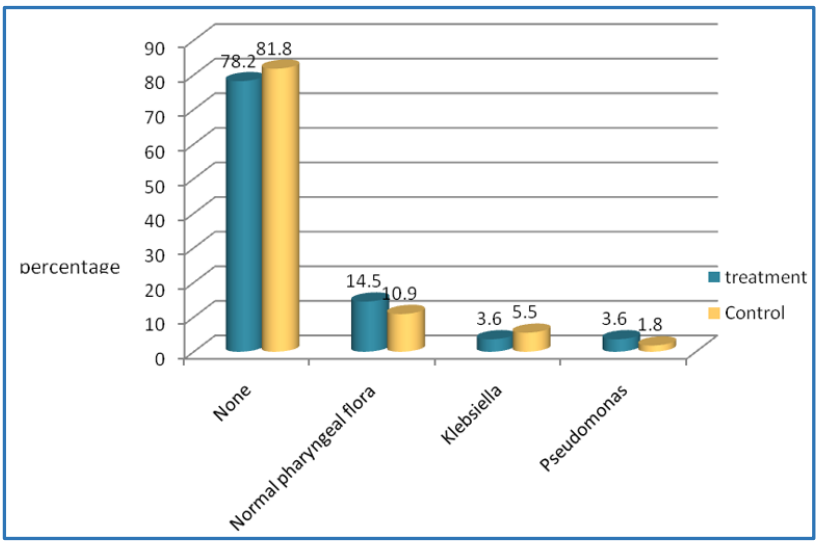

Figure 1. Sputum Culture Reports of Treatment and Control Groups (p value 0.834)

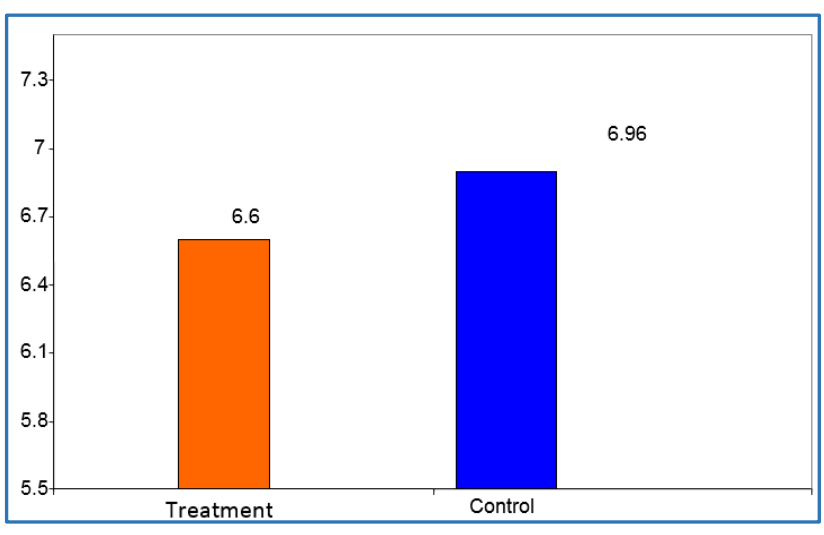

Figure 2. Mean Duration of Hospital Stay in Days (p value 0.421)

\begin{tabular}{|c|c|c|c|c|c|c|}
\hline \multirow{3}{*}{ Group } & \multirow{3}{*}{$\begin{array}{c}\text { Disease } \\
\text { Stage }\end{array}$} & \multicolumn{4}{|c|}{ Days as IP } & \multirow{3}{*}{$\mathbf{p}$} \\
\hline & & \multicolumn{2}{|c|}{$<=7$ Days } & \multicolumn{2}{|c|}{$>7$ Days } & \\
\hline & & Count & $\%$ & Count & $\%$ & \\
\hline \multirow{4}{*}{ Treatment } & Grade 1 & 6 & 14.6 & 0.0 & 0.0 & \multirow{4}{*}{$<0.001$} \\
\hline & Grade 2 & 26 & 63.4 & 2.0 & 14.3 & \\
\hline & Grade 3 & 9 & 22.0 & 6.0 & 42.9 & \\
\hline & Grade 4 & 0 & 0.0 & 6.0 & 42.9 & \\
\hline \multirow{4}{*}{ Control } & Grade 1 & 4 & 12.1 & 1.0 & 4.5 & \multirow{4}{*}{0.018} \\
\hline & Grade 2 & 22 & 66.7 & 8.0 & 36.4 & \\
\hline & Grade 3 & 7 & 21.2 & 10.0 & 45.5 & \\
\hline & Grade 4 & 0 & 0.0 & 3.0 & 13.6 & \\
\hline
\end{tabular}

Table 3. Disease Severity and Duration of Hospital Stay

\begin{tabular}{|c|c|c|c|c|}
\hline \multirow{2}{*}{$\begin{array}{l}\text { Relapse } \\
\text { in } 2 \text { Weeks }\end{array}$} & \multicolumn{2}{|c|}{ Treatment } & \multicolumn{2}{|c|}{ Control } \\
\hline & Count & Percent & Count & Percent \\
\hline 0 & 25 & 45.5 & 26 & 47.3 \\
\hline 1 & 21 & 38.2 & 21 & 38.2 \\
\hline 2 & 8 & 14.5 & 6 & 10.9 \\
\hline 3 & 1 & 1.8 & 2 & 3.6 \\
\hline \multicolumn{5}{|c|}{$\begin{array}{l}\text { Table 4. Comparison of the Number of Relapses } \\
\text { in Two Weeks Between Treatment and Control Groups }\end{array}$} \\
\hline
\end{tabular}

The number of relapses in two weeks were almost similar in the two groups as is evident from Table 4.

There was a significant relationship between duration of stay and cor pulmonale both in Treatment group and Control group. The p value was 0.023 and 0.004 respectively. Only 
$16.7 \%$ of Treatment group and $20.7 \%$ of Controls with cor pulmonale had relapse in 2 weeks. The relationship was not significant. The $\mathrm{p}$ value was 0.947 and 0.611 among Treatment and Control groups respectively.

There was no significant relationship between number of relapses in two weeks and age of the patient, stage of the disease, smoking index, presence of cor pulmonale, etc. Similarly, age and smoking index had no relation with the duration of hospital stay also. However, a significant relation was found between the disease stage and duration of hospital stay in both treatment $(\mathrm{p}<0.001)$ and control $(\mathrm{p}<0.018)$ groups. Significant association was there between the presence of cor pulmonale and duration of hospital stay in both treatment and control groups with p values of 0.023 and 0.004 respectively.

The study also assessed the need for a routine sputum Gram stain and culture in all COPD exacerbations, even if the exacerbation is secondary to non-infective causes. This was done as a secondary objective. Gram-negative bacilli were seen in $30.9 \%$ of treatment group and $36.4 \%$ of control group. Gram-positive cocci were isolated in 1 case each in both the groups. This finding was not statistically significant $(\mathrm{p}=0.831)$.

Sputum culture and sensitivity yielded no organism growth in $78.2 \%$ of the treatment group and $81.8 \%$ of the control group. Pathogenic organisms were grown in 4 patients each in both groups. The rest showed normal pharyngeal flora growth in culture of sputum. The distribution is shown in Figure 1. This too was not statistically significant ( $p=0.834)$.

\section{DISCUSSION}

Our study concluded that there was no significant advantage of using antibiotics routinely in all COPD exacerbations without any clinical evidence of infection, in terms of the number of relapses or the duration of hospital stay. This has been recommended in the GOLD guidelines too.(2) Comparable findings were observed in other studies $(3,4,5)$ by Wim et al and Ram et al. If this practice is followed, we can control the overzealous use of antibiotics in COPD and the emergence of antibiotic resistance.

The study also showed that the stage of COPD and the presence of cor pulmonale were significant in determining the duration of hospital stay. But these did not affect the number of relapses. Other studies have come up with factors affecting the length of hospital stay in COPD exacerbations. $(6,7)$ Disease stage including presence of cor pulmonale is one among the factors studied and the results are comparable to ours.

Later studies have shown use of biomarkers like CRP, procalcitonin, etc. to identify patients with COPD exacerbations requiring antibiotic therapy. $(8,9,10)$ This may soon get integrated into the guidelines for using antibiotics in COPD exacerbations.

Literature clearly says that half of all COPD exacerbations are due to infections, bacterial or viral. Studies investigating the bacterial isolates in COPD exacerbations state that most of the infections are by Haemophilus influenzae, Moraxella catarrhalis and Streptococcus pneumoniae. A recent study by Dalia et al shows a pathogenic organism in culture of sputum in two third of the samples studied. Majority of the isolates were Streptococcus pneumoniae (43.3\%) in this study.(11) Whether to give antibiotics to all exacerbations of COPD is still a debated question. Most studies favour their use with an infective exacerbation. GOLD guidelines also advocate the same. ${ }^{(4,12)} \mathrm{A}$ systematic review by Milo et al describes how the use of antibiotics in severe exacerbations of COPD effectively reduces treatment failure and mortality rates. The review says antibiotics may not be generally indicated in mild-tomoderate exacerbations.(13)

\section{CONCLUSION}

Based on our findings, we conclude that apart from the fact that empirical antibiotics are not useful in COPD exacerbations without any clinical or radiological evidence of infection, a routine Gram staining and culture is also not indicated in these cases. The Gram stain and culture positivity also did not have any significant impact on the number of relapses in these patients.

\section{REFERENCES}

[1] Anthonisen NR, Manfreda J, Warren CP, et al. Antibiotic therapy in exacerbations of chronic obstructive pulmonary disease. Ann Intern Med 1987;106(2):196-204.

[2] The global initiative for obstructive lung disease home page 2016. Available from: http://www.goldcopd.com.

[3] Daniels JM, Snijders D, de Graaff CS, et al. Antibiotics in addition to systemic corticosteroids for acute exacerbations of chronic obstructive pulmonary disease. Am J Respir Crit Care Med 2010;181(2):1507.

[4] Ram FS, Rodriguez-Roisin R, Granados-Navarrete A, et al. Antibiotics for exacerbations of chronic obstructive pulmonary disease. Cochrane Database Syst Rev 2006;2:CD004403.

[5] Boersma WG. Antibiotics in acute exacerbations of COPD: the good, the bad and the ugly. European Respiratory Journal 2012;40:1-3.

[6] Wang Y, Stavem K, Dahl FA, et al. Factors associated with a prolonged length of stay after acute exacerbation of chronic obstructive pulmonary disease (AECOPD). Int J Chron Obstruct Pulmon Dis 2014;9:99-105.

[7] Dewan NA, Rafique S, Kanwar B, et al. Acute exacerbation of COPD: factors associated with poor treatment outcome. Chest 2000;117(3):662-71.

[8] Hurst JR, Donaldson GC, Perera WR, et al. Use of plasma biomarkers at exacerbation of chronic obstructive pulmonary disease. Am J Respir Crit Care Med 2006;174(8):867-74.

[9] Stolz D, Christ-Crain M, Bingisser R, et al. Antibiotic treatment of exacerbations of COPD: a randomized, controlled trial comparing procalcitonin-guidance with standard therapy. Chest 2007;131(1):9-19.

[10] Daniels JM, Schoorl M, Snijders D, et al. Procalcitonin vs C-reactive protein as predictive markers of response to antibiotic therapy in acute exacerbations of COPD. Chest 2010;138(5):1108-15. 
[11] ElFeky DS, Elmandory HM, Galal M, et al. Sputum Bacteriology in Patients with Acute Exacerbation of Chronic Obstructive Pulmonary Disease. Int J Curr Microbiol App Sci 2016;5(1):289-305.

[12] Qureshi H, Sharafkhaneh A, Hanania NA. Chronic obstructive pulmonary disease exacerbations: latest evidence and clinical implications. Ther Adv Chronic Dis 2014;5(5):212-27.
[13] Puhan MA, Vollenweider D, Latshang T, et al. Exacerbations of chronic obstructive pulmonary disease: when are antibiotics indicated? A systematic review. Respir Res 2007;8(1):30. 